\title{
Rapid diagnostics of orthopedic implant-associated infections using Unyvero ITI implant and tissue infection application is not optimal for Staphylococcus species identification
}

\author{
Hege Vangstein Aamot ${ }^{1,2^{*}} \mathbb{D}$, Bjørn Odd Johnsen ${ }^{1,4}$ and Inge Skråmm ${ }^{3}$
}

\begin{abstract}
Objectives: This pilot study aimed to compare the commercial Unyvero ITI multiplex PCR application (U-ITI, Curetis $\mathrm{GmbH}$ ) with conventional culturing concerning (a) detection of pathogens, (b) time to detection of pathogens and (c) time to and quality of antibiotic treatment recommendation in diagnostics of orthopedic implant-associated infections (OIAI).

Results: 72 tissue biopsies from 15 consecutive patients with deep OIAl infections were analyzed with conventional culturing including phenotypic antibiotic susceptibility testing and the U-ITI. U-ITI showed lower sensitivity than conventional culturing concerning detection of pathogens (73\% vs 93\%). 4/15 patients would have been given false negative results by U-ITI, all of which were culture-positive for Staphylococcus species. Median time to detection of pathogens was $47 \mathrm{~h}$ and antibiotic resistance $89 \mathrm{~h}$ by conventional methods compared to $13.5 \mathrm{~h}$ with the U-ITI. The U-ITI did not detect antibiotic resistance, whereas conventional culturing showed resistance to antibiotics covered by the U-ITI panel in 2 patients. Time to detection of pathogens was improved, but the detection limit for staphylococci was unsatisfactory. Although the time to antibiotic treatment recommendation was significantly reduced, the U-ITI would have resulted in incorrect antibiotic recommendation in 2 patients. Our data do not support use of this assay in diagnostics.
\end{abstract}

Keywords: Rapid diagnostics, Implant infection, Staphylococcus aureus, Unyvero ITI, Orthopedic

\section{Introduction}

The majority of orthopedic procedures involve the use of implants. Implants dramatically increase the risk of infection [1]. Although these infections are infrequent, with an overall surgical site infection rate following implant surgery of $3 \%$ [2], the number of patients undergoing orthopedic implant surgery increases.

Current standard procedure for identification of the microbes causing these infections is extensive [3] and

\footnotetext{
*Correspondence: heg0@ahus.no
}

${ }^{1}$ Department of Microbiology and Infection Control, Akershus University Hospital, Lørenskog, Norway

Full list of author information is available at the end of the article only few diagnostic tools for rapid diagnostics of orthopedic implant-associated infections (OIAI) with varying degrees of sensitivity and specificity are available $[4,5]$. However, the commercial Unyvero ITI multiplex-PCR application (U-ITI) for identification of implant and tissue infections (Curetis GmbH, Holzgerlingen, Germany) can detect selected pathogens and antibiotic resistance markers within a few hours analyzing more than 100 DNA targets simultaneously. This allows for more expeditious microbe identification and administration of targeted treatment than conventional culturing.

This study aims to compare the U-ITI assay to conventional culturing in diagnosing orthopedic 
implant-associated infections (OIAI). The parameters compared include (a) detection of pathogens, (b) time to detection of pathogens, and (c) time to and quality of antibiotic treatment recommendations.

\section{Main text \\ Materials and methods}

Patients with acute, clinically defined deep OIAIs necessitating revision surgery from January through August 2017 at Akershus University Hospital, Lørenskog, Norway were eligible for inclusion. The criteria for an OIAI were based on the standards described by Parvizi [6] with a clinically motivated adjustment for patient ID 101.

Diagnostic soft tissue biopsies were routinely collected intraoperatively. According to international consensus, 5 biopsies should be collected [3]. If more than 5 tissue biopsies were collected, 5 biopsies were selected at random for Unyvero analysis. In cases with less than 5 biopsies, all were included. No patients received antibiotics prior to surgery, except for patient ID 101 who received penicillin due to a skin infection. According to conventional guidelines, empirical treatment were started after biopsies were taken.

All biopsies were cut into three: one followed standard culture procedure, one was analyzed with Unyvero, and the last was stored at $-80{ }^{\circ} \mathrm{C}$. If it was not possible to perform the Unyvero analysis within $48 \mathrm{~h}$ of surgery, the biopsies were stored at $-80{ }^{\circ} \mathrm{C}$. Otherwise, the biopsies were analyzed consecutively and temporarily stored at $4{ }^{\circ} \mathrm{C}$.

Standard culturing was performed by homogenizing the sample with mortar and pistil in Mueller-Hinton broth in a type 2 microbiological safety cabinet with subsequent seeding, using a modified quadrant streak technique with only 3 "quadrants", of:

1. 1 blood agar plate (incubation 5 days aerobically at $35{ }^{\circ} \mathrm{C}$ with a regular atmosphere supplemented with $5 \% \mathrm{CO}_{2}$ ).

2. 1 chocolate agar plate incubated aerobically as described for 5 days.

3. 1 plate of tryptose soy agar base supplemented with $5 \%$ defibrinated sheep blood, $0.001 \%$ vitamin $\mathrm{K}$, $0.0005 \%$ hemin, $0.1 \%$ glucose and $0.03 \%$ yeast extract (incubation 5 days in anaerobic chamber at $35{ }^{\circ} \mathrm{C}$ with an atmosphere containing $10 \% \mathrm{CO}_{2}, 10 \% \mathrm{H}_{2}$ and $80 \% \mathrm{~N}_{2}$ ),

4. 1 Mueller-Hinton broth (incubation aerobically for 2 days before subcultivation to a blood agar plate and a chocolate agar plate incubated aerobically for another 3 days).
All agars and broths were manufactured by the department's own media production unit. Bacterial growth was semiquantified using the designations sparse, moderate or rich growth. The colonies were subcultured in the relevant atmosphere and identified by matrix assisted laser desorption ionization time of flight (MALDI-TOF) using MALDI-TOF MS Biotyper (Bruker Daltonik GmbH, Bremen, Germany, MBT 6903 MSP Library, MBT Compass v4.1.70.1, Compass for flexControl v3.4). A specific bacterium had to be growing in at least 2 tissue biopsies or be detected by U-ITI in at least 2 tissue biopsies per patient to be considered positive. Antibiotic susceptibility testing was performed according to the guideline from the European Committee on Antimicrobial Susceptibility Testing EUCAST [7] and EUCAST breakpoints were utilized to categorize the isolate as sensitive (S), intermediate (I) or resistant (R) [8].

Time to pathogen detection was defined as the time from sampling the tissue biopsy to the time of pathogen identification. Similarly, time to antibiotic treatment recommendation and complete results, were defined as the time from sampling of tissue biopsy to time of reporting the results of antibiotic susceptibility testing and all other results, including anaerobic cultivation.

The Unyvero U-ITI assay consists of a sample tube with pre-treatment buffer, a sealed master mix tube and a cartridge where the multiplex PCR is performed. The results are reported as positive or negative for each microbe/ resistance marker and the degree of positivity is reported as 1-3 green boxes. Unyvero analysis was performed on the Unyvero system, consisting of a lysator, analyser and cockpit, as recommended by the manufacturer (Curetis $\mathrm{GmbH}$, Holzgerlingen, Germany). The analyzer can perform multiplex-PCR on 2 tissue samples at a time. When analyzing 5 tissue samples, the total time from biopsy to finished results would be approximately $\sim 13.5 \mathrm{~h}$ if analyzed consecutively.

Sensitivity of both methods was calculated as the number of patients that were positive for a pathogen in at least two biopsies divided on the total number of patients that had a clinically defined infection.

\section{Results}

\section{Detection of pathogen}

72 tissue biopsies from 15 consecutive patients were included. 9 (60\%) patients were females and median age was 72 years [range: $42-88$ years]. The criteria met for OIAI for each patient are presented in Additional file 1 . The infected implants were joint prosthesis in 10 patients, and osteosynthetic devices in 5 patients. Of the 72 biopsies, 50 were analyzed consecutively, whereas 22 biopsies were analyzed after storage in $-80{ }^{\circ} \mathrm{C}$. The distribution of results from culture and Unyvero results is 
presented in Table 1. Detailed results from identification of the pathogens by the two different methods are presented in Table 2. Standard culturing methods showed higher sensitivity than the Unyvero ITI application with 62 versus 43 positive tissue biopsies (Table 1 ). The biopsies only positive by culturing included 18 biopsies positive for Staphylococcus aureus and 8 biopsies positive for Staphylococcus epidermidis. 4 patients suffering from OIAI with S. aureus, coagulase negative staphylococci or both, would not have had an aetiological diagnosis using U-ITI alone. Conversely, U-ITI identified the pathogen in 6 culture-negative tissue biopsies from two patients (Table 2, IDs 101 and 115) which were positive for Propionibacterium acnes and/or Streptococcus pneumoniae. In addition, U-ITI identified two additional bacteria from one patient (coagulase negative staphylococci and Finegoldia magna in addition to Corynebacterium species, Table 2, ID102). Sensitivity on the patient level was $93 \%$ (CI $68-100 \%, 14 / 15$ patients) for culturing, whereas sensitivity for Unyvero was 73\% (CI 45-92\%, 11/15 patients).

\section{Response times}

Median time to detection of pathogen by conventional culturing was $47 \mathrm{~h}$ [range: $20-168 \mathrm{~h}$ ], whereas median time to results from antibiotic sensitivity was $89 \mathrm{~h}$ [range: 44-192 h]. Median time to final results, including results from anaerobic culturing, was $143 \mathrm{~h}$ [range: 106-192 h] by conventional methods. The corresponding analysis time for U-ITI would be a maximum of $13.5 \mathrm{~h}$ if analyzed consecutively.

\section{Quality of antibiotic treatment advice}

Phenotypic identification of antibiotic resistance and its correlation with genes detectable by U-ITI are presented in Table 3. U-ITI identified no resistance genes. Conventional phenotypic testing was able to detect resistance to several antibiotics, however, none of the antibiotic resistance phenotypes detected here are among those detectable by the U-ITI. Additionally, in a total of 4 biopsies from 2 patients U-ITI gave false negative results.

Table 1 Distribution of results of conventional culturing versus Unyvero ITI multiplex PCR of 72 biopsies from 15 patients with orthopaedic implant-associated infections

\begin{tabular}{lccc}
\hline & Unyvero negative & Unyvero positive & Total \\
\hline Culture negative & $4(0)$ & $6(1)$ & $10(1)$ \\
Culture positive & $25^{\mathrm{a}}(4)$ & $37^{\mathrm{a}}(10)$ & $62(14)$ \\
Total & $29(4)$ & $43(11)$ & $72(15)$ \\
\hline
\end{tabular}

The number of patients affected when the results from all biopsies are considered is given in parenthesis

a Including 1 invalid of a total of 8 multiplex-PCR Unyvero

\section{Discussion}

The U-ITI was inadequate in rapid identification of bacteria and antibiotic resistance. The sensitivity was $73 \%$ for U-ITI compared to a sensitivity of $93 \%$ for conventional culturing. The inadequacy was particularly evident in the detection of $S$. aureus as 18 biopsies positive for $S$. aureus by standard culturing were negative by the U-ITI (Table 2). Additionally, 8 culture-positive biopsies for S. epidermidis resulted in U-ITI false-negatives (Table 2). 4 patients suffering from OIAI caused by staphylococci, 3 of which involving $S$. aureus, would have remained undiagnosed utilizing U-ITI alone. These results may be explained by the U-ITI detection limits as the bacteria in these cases were quantified as "sparse growth" or cultivated after broth enrichment (Table 1). The detection limit is reported by the U-ITI manufacturer to be $10^{5}$ pathogens $/ \mathrm{mL}$ of $S$. aureus and $10^{4}$ pathogens $/ \mathrm{mL}$ for coagulase negative staphylococci (CNS). As Staphylococcus species are common causes of orthopedic implant-associated infection [9], improving the detection limit for Staphylococcus species in particular would improve the usability of U-ITI. The differentiation of Staphylococcus lugdunensis from other CNS would also be preferable, as this bacterium is more virulent and should be interpreted more like $S$. aureus than other CNS $[10,11]$. Other studies have reported challenges with detection of microbes in OIAI using the U-ITI [12-15].

In the present study, the U-ITI also identified the pathogen in 6 culture-negative tissue biopsies from 2 patients. Patient 101 was previously positive for S. pneumoniae in blood culture and patient 115 was positive for $P$. acnes (now Cutibacterium acnes) in 2/5 cultured tissue biopsies. All 5 biopsies were positive for $P$. acnes with the U-ITI system, suggesting that these samples were true positives.

According to international consensus, at least 2 of the 5 biopsies have to be positive for a microbe to be scored as positive [3]. As the Unyvero system can only analyze 2 biopsies at a time, it will take in excess of $13.5 \mathrm{~h}$ to diagnose 1 patient. However, if the 2 biopsies analyzed in the first run are positive for the same bacteria, results can be given after $\sim 5 \mathrm{~h}$. Of the 15 patients included in our study, 11 were positive for bacteria in all biopsies meaning that the U-ITI system would have the potential to give same day results in $73 \%$ of the patients. The median time to detection of pathogen was $47 \mathrm{~h}$ [range: $20-168 \mathrm{~h}$ ] by conventional methods. Hence, the U-ITI system could reduce time to detection of the pathogen considerably.

There are studies investigating the use of synovial and sonication fluid, making it possible to analyze only 1 sample per patient and thereby reducing the time to detection of pathogen to $\sim 5 \mathrm{~h}[12-14,16-19]$. However, 
Table 2 Identification of pathogens by conventional culturing and Unyvero ITI application of 72 tissue biopsies from 15 orthopaedic patients with orthopaedic implant-associated infections

\begin{tabular}{|c|c|c|c|c|c|c|c|c|c|}
\hline \multirow[t]{2}{*}{ Patient } & \multirow{2}{*}{$\begin{array}{l}\text { Biopsy } \\
\text { number }\end{array}$} & \multicolumn{5}{|c|}{ Standard culturing } & \multicolumn{3}{|l|}{ Unyvero analysis } \\
\hline & & $\begin{array}{l}\text { Time } \\
\text { to detection } \\
\text { of pathogens } \\
\text { (h) }\end{array}$ & $\begin{array}{l}\text { Time } \\
\text { to recommendation } \\
\text { antibiotic treatment } \\
\text { (h) }\end{array}$ & $\begin{array}{l}\text { Time } \\
\text { to complete } \\
\text { results (h) }\end{array}$ & Pathogen ID & $\begin{array}{l}\text { Growth } \\
\text { quantification }\end{array}$ & Pathogen ID & $\begin{array}{l}\text { Degree of PCR } \\
\text { positivity } \\
\text { (1-3) }\end{array}$ & $\begin{array}{l}\text { Tissue } \\
\text { frozen prio } \\
\text { to analysis }\end{array}$ \\
\hline 101 & 1 & & & 137.7 & Neg & - & $\mathrm{Neg}$ & - & \\
\hline \multirow[t]{2}{*}{101} & 2 & & & & Neg & - & S.pneumoniae & 2 & \\
\hline & & & & & & & P.acnes & 1 & \\
\hline 101 & 3 & & & & $\mathrm{Neg}$ & - & $\mathrm{Neg}^{\mathrm{a}}$ & - & \\
\hline 101 & 4 & & & & $\mathrm{Neg}$ & - & S.pneumoniae & 2 & \\
\hline 101 & 5 & & & & $\mathrm{Neg}$ & - & S.pneumoniae & 1 & \\
\hline 102 & 1 & 65.0 & 88.6 & 186.2 & C. jeikeium & Broth only & CNS & 1 & \\
\hline 102 & 2 & & & & C.jeikeium & Sparse & Corynebacterium spp. & 1 & \\
\hline 102 & 3 & & & & C. jeikeium & Broth only & Corynebacterium spp. & 1 & \\
\hline 102 & 5 & & & & C.jeikeium & Broth only & Neg & - & Yes \\
\hline 102 & 6 & & & & C.jeikeium & Broth only & F. magna & 2 & Yes \\
\hline 104 & 1 & 68.7 & 192.3 & 192.3 & S. lugdunensis & Sparse & CNS & 3 & \\
\hline 104 & 2 & & & & S. lugdunensis & Sparse & CNS & 2 & \\
\hline \multirow[t]{2}{*}{104} & 3 & & & & S. lugdunensis & Sparse & $\mathrm{Neg}$ & - & \\
\hline & & & & & P.acnes & Sparse & & & \\
\hline 104 & 4 & & & & S. lugdunensis & Sparse & CNS & 2 & \\
\hline \multirow[t]{2}{*}{104} & 5 & & & & S. lugdunensis & Sparse & $\mathrm{Neg}^{\mathrm{a}}$ & - & \\
\hline & & & & & P.acnes & Sparse & & & \\
\hline 105 & 1 & 58.7 & 156.0 & 156.0 & $\mathrm{Neg}$ & - & $\mathrm{Neg}$ & - & \\
\hline \multirow[t]{2}{*}{105} & 2 & & & & S. aureus & Broth only & $\mathrm{Neg}$ & - & \\
\hline & & & & & S. epidermidis & Broth only & & & \\
\hline \multirow[t]{3}{*}{105} & 3 & & & & S. aureus & Sparse & Neg & - & \\
\hline & & & & & S. epidermidis & Broth only & & & \\
\hline & & & & & S. capitis & Sparse & & & \\
\hline \multirow[t]{2}{*}{105} & 4 & & & & S. aureus & Broth only & Neg & - & \\
\hline & & & & & S. epidermidis & Broth only & & & \\
\hline \multirow[t]{2}{*}{105} & 5 & & & & S. aureus & Sparse & Neg & - & \\
\hline & & & & & S. epidermidis & Broth only & & & \\
\hline 107 & 1 & 96.0 & 96.0 & 170.8 & S. epidermidis & Sparse & Neg & - & \\
\hline 107 & 2 & & & & S. epidermidis & Broth only & $\mathrm{Neg}$ & - & \\
\hline 107 & 3 & & & & S. epidermidis & Sparse & $\mathrm{Neg}$ & - & \\
\hline 107 & 4 & & & & S. epidermidis & Broth only & $\mathrm{Neg}$ & - & \\
\hline 107 & 5 & & & & Neg & - & Neg & - & \\
\hline 108 & 1 & 24.3 & 47.8 & 122.8 & S. aureus & Sparse & S. aureus & 2 & \\
\hline 108 & 2 & & & & S. aureus & Sparse & S. aureus & 1 & \\
\hline 108 & 3 & & & & S. aureus & Sparse & S. aureus & 1 & \\
\hline 108 & 4 & & & & S. aureus & Sparse & S. aureus & 1 & \\
\hline 108 & 5 & & & & S. aureus & Sparse & S. aureus & 1 & \\
\hline 109 & 1 & 43.1 & 63.6 & 137.1 & S. aureus & Sparse & Neg & - & \\
\hline 109 & 2 & & & & S. aureus & Sparse & $\mathrm{Neg}$ & - & Yes \\
\hline 109 & 3 & & & & S. aureus & Sparse & $\mathrm{Neg}$ & - & \\
\hline 109 & 4 & & & & S. aureus & Sparse & Neg & - & \\
\hline 109 & 5 & & & & S. aureus & Sparse & $\mathrm{Neg}$ & - & \\
\hline 110 & 1 & & & 105.8 & S. aureus & Sparse & Neg & - & \\
\hline 110 & 2 & & & & S. aureus & Sparse & Neg & - & \\
\hline 110 & 3 & & & & S. aureus & Sparse & Neg & - & \\
\hline 110 & 4 & & & & S. aureus & Sparse & $\mathrm{Neg}$ & - & \\
\hline
\end{tabular}


Table 2 (continued)

\begin{tabular}{|c|c|c|c|c|c|c|c|c|c|}
\hline \multirow[t]{2}{*}{ Patient } & \multirow{2}{*}{$\begin{array}{l}\text { Biopsy } \\
\text { number }\end{array}$} & \multicolumn{5}{|c|}{ Standard culturing } & \multicolumn{3}{|c|}{ Unyvero analysis } \\
\hline & & $\begin{array}{l}\text { Time } \\
\text { to detection } \\
\text { of pathogens } \\
\text { (h) }\end{array}$ & $\begin{array}{l}\text { Time } \\
\text { to recommendation } \\
\text { antibiotic treatment } \\
\text { (h) }\end{array}$ & $\begin{array}{l}\text { Time } \\
\text { to complete } \\
\text { results (h) }\end{array}$ & Pathogen ID & $\begin{array}{l}\text { Growth } \\
\text { quantification }\end{array}$ & Pathogen ID & $\begin{array}{l}\text { Degree of PCR } \\
\text { positivity } \\
(1-3)\end{array}$ & $\begin{array}{l}\text { Tissue } \\
\text { frozen prior } \\
\text { to analysis }\end{array}$ \\
\hline 110 & 5 & & & & S. aureus & Sparse & Neg & - & \\
\hline 111 & 1 & 53.6 & 76.1 & 147.3 & S. aureus & Rich & S. aureus & 2 & \\
\hline 111 & 2 & & & & S. aureus & Rich & S. aureus & 2 & Yes \\
\hline 111 & 4 & & & & S. aureus & Rich & S. aureus & 2 & \\
\hline 111 & 5 & & & & S. aureus & Rich & S. aureus & 2 & \\
\hline 111 & 6 & & & & S. aureus & Rich & S. aureus & 2 & \\
\hline 112 & 1 & 46.6 & 46.6 & 143.7 & S. aureus & Sparse & S. aureus & 2 & Yes \\
\hline 112 & 2 & & & & S.aureus & Sparse & S. aureus & 2 & Yes \\
\hline 112 & 3 & & & & S. aureus & Rich & S. aureus ${ }^{\mathrm{a}}$ & 3 & Yes \\
\hline 112 & 4 & & & & S. aureus & Sparse & S. aureus & 2 & Yes \\
\hline 113 & 1 & 23.5 & 43.9 & 142.9 & S. aureus & Rich & S. aureus & 2 & Yes \\
\hline 113 & 2 & & & & S. aureus & Rich & S. aureus & 2 & Yes \\
\hline 113 & 3 & & & & S. aureus & Rich & S. aureus & 2 & Yes \\
\hline 113 & 4 & & & & S. aureus & Rich & S. aureus & 2 & Yes \\
\hline 114 & 1 & 24.3 & 46.1 & 120.2 & S. aureus & Rich & S. aureus & 2 & Yes \\
\hline 114 & 2 & & & & S. aureus & Moderate & S. aureus & 2 & Yes \\
\hline 114 & 3 & & & & S. aureus & Rich & S. aureus & 3 & Yes \\
\hline 114 & 4 & & & & S. aureus & Moderate & S. aureus & 2 & Yes \\
\hline 114 & 5 & & & & S. aureus & Moderate & S. aureus & 2 & Yes \\
\hline 115 & 1 & & & 167.7 & Neg & - & P.acnes & 2 & Yes \\
\hline 115 & 2 & & & & Neg & - & P. acnes & 1 & Yes \\
\hline 115 & 3 & & & & Neg & - & P. acnes & 2 & Yes \\
\hline 115 & 4 & & & & P. acnes & Sparse & P. acnes & 3 & Yes \\
\hline 115 & 5 & & & & P. acnes & Sparse & P. acnes & 1 & Yes \\
\hline 116 & 1 & 26.7 & 69.3 & 119.2 & S. aureus & Sparse & Neg & - & \\
\hline 116 & 2 & & & & S. aureus & Sparse & S. aureus & 1 & \\
\hline 116 & 3 & & & & S. aureus & Sparse & S. aureus & 1 & \\
\hline 116 & 4 & & & & S. aureus & Sparse & Neg & - & \\
\hline 116 & 5 & & & & S. aureus & Sparse & S. aureus & 1 & \\
\hline 117 & 1 & 20.3 & 115.7 & 115.7 & S. aureus & Moderate & S. aureus & 1 & \\
\hline 117 & 2 & & & & S. aureus & Sparse & Neg & - & \\
\hline 117 & 3 & & & & S. aureus & Sparse & S. aureus & 1 & \\
\hline 117 & 4 & & & & S. aureus & Sparse & Neg & - & \\
\hline
\end{tabular}

a One PCR chamber invalid

Neg negative, CNS coagulase negative staphylocci, spp. species

limited sensitivity is still an issue, as also concluded in a recent multi-center study [20].

The U-ITI includes a range of antibiotic resistance markers. As median time to phenotypic antibiotic sensitivity test (time to definite antibiotic treatment) was $89 \mathrm{~h}$ [range: $44-192 \mathrm{~h}$ ] by standard methods, the reduction of time can be improved even more using the U-ITI. However, being in an area with a relatively low prevalence of multi-drug resistance, the antibiotic resistance genes included in the U-ITI did not contribute in improving time to correct treatment in the current study. To be beneficial in similar areas inclusion of additional antibiotic resistance genes is warranted. It would improve U-ITI's utility to include in the panel genes for resistance of important antibiotics in treating orthopedic implantassociated infections such as quinolone and rifampicin resistance genes.

In conclusion, time to detection of pathogens was improved by using the U-ITI. However, the sensitivity of U-ITI compared to conventional cultivation was too low to permit clinical use before the detection limit for Staphylococcus species in particular has 
Table 3 Antibiotic resistance: phenotypic identification with conventional methods versus genotypic identification with Unyvero ITI application of 72 tissue biopsies from 15 patients with orthopaedic implant-associated infection

\begin{tabular}{|c|c|c|c|c|}
\hline \multicolumn{3}{|l|}{ Standard phenotypic identification } & \multirow{2}{*}{$\begin{array}{l}\text { Possible genotypic } \\
\text { identification- } \\
\text { Unyvero }{ }^{b, c}\end{array}$} & \multirow{2}{*}{$\begin{array}{l}\text { Relevant for the following } \\
\text { species detected in this pilot }\end{array}$} \\
\hline Antibiotics tested & $\begin{array}{l}\mathrm{N} \text { resistant microbes/N } \\
\text { microbes tested }^{\mathrm{a}}\end{array}$ & $\begin{array}{l}\text { Patient ID } \\
\text { of patients } \\
\text { with resistant } \\
\text { microbes }\end{array}$ & & \\
\hline Cefoxitin (methicillin resistance screening) & $1 / 13$ & 107 & $\underline{\text { mecA, mecC }}$ & Staphylococcus spp. \\
\hline \multirow[t]{2}{*}{ Ciprofloxacin } & \multirow[t]{2}{*}{$2 / 13$} & \multirow[t]{2}{*}{107,117} & \multirow[t]{2}{*}{-} & Corynebacterium spp. \\
\hline & & & & Staphylococcus spp \\
\hline \multirow[t]{2}{*}{ Erythromycin } & \multirow[t]{2}{*}{$1 / 13$} & \multirow[t]{2}{*}{107} & \multirow[t]{2}{*}{ ermA, ermC } & Staphylococcus spp. \\
\hline & & & & Streptococcus pneumoniae \\
\hline Fusidic acid & $3 / 13$ & $105 \times 2,107$ & - & Staphylococcus spp. \\
\hline \multirow[t]{2}{*}{ Gentamicin } & \multirow[t]{2}{*}{$0 / 14$} & & \multirow[t]{2}{*}{$\left.\underline{\operatorname{aa}\left(6^{\prime}\right)}\right) \operatorname{aph}\left(2^{\prime \prime}\right), \underline{\operatorname{aacA} 4}$} & Corynebacterium spp. \\
\hline & & & & Staphylococcus spp. \\
\hline Clindamycin & $2 / 15$ & 102,107 & $\underline{\text { ermA, ermC }}$ & All \\
\hline \multirow[t]{4}{*}{ Chloramphenicol } & \multirow[t]{4}{*}{$0 / 9$} & & \multirow[t]{4}{*}{-} & Finegoldia magna \\
\hline & & & & Propionibacterium acnes \\
\hline & & & & Staphylococcus spp. \\
\hline & & & & Streptococcus pneumoniae \\
\hline \multirow[t]{3}{*}{ Linezolid } & \multirow[t]{3}{*}{$0 / 13$} & & \multirow[t]{3}{*}{-} & Corynebacterium spp. \\
\hline & & & & Staphylococcus spp. \\
\hline & & & & Streptococcus pneumoniae \\
\hline \multirow[t]{4}{*}{ Meropenem $^{c}$} & \multirow[t]{4}{*}{$1 / 14^{c}$} & & \multirow{4}{*}{$\begin{array}{l}\text { kpc, imp, ndm, oxa- } 23 \text {, } \\
\text { oxa-24/40, oxa-48, oxa- } \\
58, \text { vim }\end{array}$} & Finegoldia magna \\
\hline & & & & Propionibacterium acnes \\
\hline & & & & Staphylococcus spp.c \\
\hline & & & & Streptococcus pneumoniae \\
\hline Metronidazole & $1 / 1$ & 104 & - & Finegoldia magna \\
\hline Penicillin & $11 / 14$ & $\begin{array}{l}102,104,105 \times 2 \\
108,109,111,113 \\
114,116,117\end{array}$ & - & All \\
\hline \multirow[t]{4}{*}{ Piperacillin Tazobactamc } & \multirow[t]{4}{*}{$1 / 14^{c}$} & & - & Finegoldia magna \\
\hline & & & & Propionibacterium acnes \\
\hline & & & & Staphylococcus spp. ${ }^{c}$ \\
\hline & & & & Streptococcus pneumoniae \\
\hline Rifampicin & $0 / 13$ & & - & Corynebacterium spp. \\
\hline & & & & Staphylococcus spp. \\
\hline & & & & Streptococcus pneumoniae \\
\hline Teicoplanin & $0 / 4$ & & $\underline{\operatorname{van} A}$ & Finegoldia magna \\
\hline & & & & Propionibacterium acnes \\
\hline & & & & Staphylococcus spp. \\
\hline & & & & Streptococcus pneumoniae \\
\hline Tetracycline & $0 / 12$ & & - & Corynebacterium spp. \\
\hline & & & & Staphylococcus spp. \\
\hline & & & & Streptococcus pneumoniae \\
\hline Trimethoprim-sulfamethoxazole & $1 / 13$ & 107 & - & Staphylococcus spp. \\
\hline & & & & Streptococcus pneumoniae \\
\hline Vancomycin & $0 / 4$ & & $\underline{\operatorname{van} A, \operatorname{van} B}$ & All \\
\hline 3rd generation cephalosporins ${ }^{d}$ & $1 / 13^{c}$ & & CTX-M & Staphylococcus spp. ${ }^{d}$ \\
\hline & & & & Streptococcus pneumoniae \\
\hline
\end{tabular}

a Patient 115 failed phenotypic antibiotic resistance testing

b Underline types indicate genes relevant for bacteria detected in this pilot

c All biopsies were negative 
Table 3 (continued)

d Phenotypically cefoxitin sensitive/genotypically mecA and mecC negative staphylococci are considered sensitive to meropenem, piperacillin-tazobactam and 3rd generation cephalosporins active against staphylococci

been optimized. Although in theory, the U-ITI would improve time to correct antibiotic treatment recommendation, it did not reveal the antibiotic resistance prevalent in our samples. Our data do not support use of this assay in diagnostics.

\section{Limitations}

This is a pilot study where the overall number of biopsies was relatively low and culture-negative biopsies were few. There was a limited number of different species detected and most genetic markers for resistance in the Unyvero panel were not relevant to the findings in this study. However, biopsies were collected from 15 consecutive patients reflecting the clinical daily life in low-resistance areas like ours. Due to lack of Unyvero reagents at the time of surgery 22 biopsies were stored at $-80{ }^{\circ} \mathrm{C}$. Storage at $-80{ }^{\circ} \mathrm{C}$ may degrade sensitive bacteria and nucleic acid and consequently lower sensitivity of the Unyvero assay. However; Unyvero identifies DNA from both dead and living microbes.

\section{Supplementary information}

Supplementary information accompanies this paper at https://doi. org/10.1186/s13104-019-4755-5.

Additional file 1. Details of criteria fulfilment for orthopaedic implantassociated infection (OIAI) on the included 15 patients based on the criteria described by Parvizi and co-workers [6].

\section{Abbreviations}

CNS: coagulase negative staphylococci; F. magna: Finegoldia magna; MALDITOF: matrix assisted laser desorption ionization time of flight; OIAl: orthopedic implant-associated infections; P. acnes: Propionibacterium acnes (now Cutibacterium acnes); S. aureus: Staphylococcus aureus; S. epidermidis: Staphylococcus epidermidis; S. pneumoniae: Streptococcus pneumoniae; U-ITI: Unyvero ITI multiplex-PCR application.

\section{Acknowledgements}

The authors thank Curetis Gmbh, Holzerligen, Germany for providing the Unyvero ITI implant and tissue infection multiplex PCR system and reagents.

\section{Authors' contributions}

HVA and IS conceived the study. HVA performed the Unyvero analyses. HVA, IS and $\mathrm{BO} J$ were involved in study design, data analysis and drafting the manuscript. All authors read and approved the final manuscript.

\section{Funding}

Curetis Gmbh, Holzerligen, Germany provided the Unyvero ITI implant and tissue infection multiplex PCR system and reagents. The company had no influence on the design or interpretation of the results in this study.

\section{Availability of data and materials}

All data generated or analyzed during this study are included in this published article and its Additional file.
Ethics approval and consent to participate

This study was approved by the Regional Committee for Medical Ethics (2016/1929) and the local Data Protection Officer (17/024). The patients consigned a written, informed consent.

\section{Consent for publication}

Not applicable.

\section{Competing interests}

The authors declare that they have no competing interests.

\section{Author details}

${ }^{1}$ Department of Microbiology and Infection Control, Akershus University Hospital, Lørenskog, Norway. ${ }^{2}$ Department of Clinical Molecular Biology (Epigen), Akershus University Hospital and University of Oslo, Lørenskog, Norway.

${ }^{3}$ Department of Orthopedic Surgery, Akershus University Hospital, Lørenskog, Norway. ${ }^{4}$ Present Address: Department of Medicine, Vestre Viken Hospital Trust, Ringerike Hospital, Hønefoss, Norway.

Received: 30 September 2019 Accepted: 18 October 2019 Published online: 06 November 2019

\section{References}

1. Zimmerli W, Waldvogel FA, Vaudaux P, Nydegger UE. Pathogenesis of foreign body infection: description and characteristics of an animal model. J Infect Dis. 1982;146(4):487-97.

2. Skråmm I, Saltyte Benth J, Bukholm G. Decreasing time trend in SSI incidence for orthopaedic procedures: surveillance matters! J Hosp Infect. 2012;82(4):243-7.

3. Osmon DR, Berbari EF, Berendt AR, Lew D, Zimmerli W, Steckelberg JM, et al. Diagnosis and management of prosthetic joint infection: clinical practice guidelines by the Infectious Diseases Society of America. Clin Infect Dis. 2013;56(1):e1-25.

4. Jun Y, Jianghua L. Diagnosis of periprosthetic joint infection using polymerase chain reaction: an updated systematic review and meta-analysis. Surg Infect. 2018;19(6):555-65.

5. Bonanzinga T, Zahar A, Dutsch M, Lausmann C, Kendoff D, Gehrke T. How reliable is the alpha-defensin immunoassay test for diagnosing periprosthetic joint infection? a prospective study. Clin Orthop Relat Res. 2017:475(2):408-15

6. Parvizi J, Zmistowski B, Berbari EF, Bauer TW, Springer BD, Della Valle CJ, et al. New definition for periprosthetic joint infection: from the Workgroup of the Musculoskeletal Infection Society. Clin Orthop Relat Res. 2011:469(11):2992-4.

7. EUCAST ESOCMaID. Antimicrobial susceptibility tesitng EUCAST disk diffusion method, version 6.0. 2017.

8. EUCAST. Breakpoint tables for interpretation of MICs and zone diameters, version 7.1, 2017. http://www.eucast.org. 2017.

9. Arciola CR, Campoccia D, Montanaro L. Implant infections: adhesion, biofilm formation and immune evasion. Nat Rev Microbiol. 2018;16(7):397-409.

10. Shah NB, Osmon DR, Fadel H, Patel R, Kohner PC, Steckelberg JM, et al. Laboratory and clinical characteristics of Staphylococcus lugdunensis prosthetic joint infections. J Clin Microbiol. 2010;48(5):1600-3.

11. Askar M, Bloch B, Bayston R. Small-colony variant of Staphylococcus lugdunensis in prosthetic joint infection. Arthroplast Today. 2018;4(3):257-60.

12. Morgenstern C, Cabric S, Perka C, Trampuz A, Renz N. Synovial fluid multiplex PCR is superior to culture for detection of low-virulent pathogens causing periprosthetic joint infection. Diagn Microbiol Infect Dis. 2018;90(2):115-9.

13. Sigmund IK, Windhager R, Sevelda F, Staats K, Puchner SE, Stenicka S, et al. Multiplex PCR Unyvero i60 ITI application improves detection of 
low-virulent microorganisms in periprosthetic joint infections. Int Orthop. 2018;43(8):1891-8.

14. Lausmann C, Zahar A, Citak M, Branes J, Schmidl S, Frommelt L, et al. Are there benefits in early diagnosis of prosthetic joint infection with multiplex polymerase chain reaction? J Bone Jt Infect. 2017;2(4):175-83.

15. Borde JP, Hacker GA, Guschl S, Serr A, Danner T, Hubner J, et al. Diagnosis of prosthetic joint infections using UMD-Universal Kit and the automated multiplex-PCR Unyvero i60 ITI((R)) cartridge system: a pilot study. Infection. 2015:43(5):551-60.

16. Hischebeth GT, Randau TM, Buhr JK, Wimmer MD, Hoerauf A, Molitor E, et al. Unyvero i60 implant and tissue infection (ITI) multiplex PCR system in diagnosing periprosthetic joint infection. J Microbiol Methods. 2016:121:27-32.

17. Prieto-Borja L, Rodriguez-Sevilla G, Aunon A, Perez-Jorge C, Sandoval E, Garcia-Canete J, et al. Evaluation of a commercial multiplex PCR (Unyvero i60((R))) designed for the diagnosis of bone and joint infections using prosthetic-joint sonication. Enferm Infecc Microbiol Clin. 2017:35(4):236-42.
18. Renz N, Feihl S, Cabric S, Trampuz A. Performance of automated multiplex PCR using sonication fluid for diagnosis of periprosthetic joint infection: a prospective cohort. Infection. 2017:45(6):877-84.

19. Villa F, Toscano M, De Vecchi E, Bortolin M, Drago L. Reliability of a multiplex PCR system for diagnosis of early and late prosthetic joint infections before and after broth enrichment. Int J Med Microbiol. 2017:307(6):363-70

20. Malandain D, Bemer P, Leroy AG, Leger J, Plouzeau C, Valentin AS, et al. Assessment of the automated multiplex-PCR Unyvero i60 ITI((R)) cartridge system to diagnose prosthetic joint infection: a multicentre study. Clin Microbiol Infect. 2018;24(1):83-e1.

\section{Publisher's Note}

Springer Nature remains neutral with regard to jurisdictional claims in published maps and institutional affiliations.
Ready to submit your research? Choose BMC and benefit from:

- fast, convenient online submission

- thorough peer review by experienced researchers in your field

- rapid publication on acceptance

- support for research data, including large and complex data types

- gold Open Access which fosters wider collaboration and increased citations

- maximum visibility for your research: over $100 \mathrm{M}$ website views per year

At BMC, research is always in progress.

Learn more biomedcentral.com/submissions 